\title{
INCLUSÃO SOCIAL NA/PELA MÍDIA: MODOS DE INSTALAÇÃO DO SUJEITO DEFICIENTE
}

\author{
PATRÍCIA APARECIDA DA SILVA ${ }^{1}$ \\ OLIMPIA MALUF-SOUZA ${ }^{2}$
}

\author{
Universidade Estadual do Estado de Mato Grosso - UNEMAT \\ Rua Dr. Gil de Campos Salles, 49. Bairro: Bosque das Palmeiras. \\ Cáceres - MT; Brasil; 78200-000 \\ patricia rogeriofilho@hotmail.com, olimpiamaluf@gmail.com
}

\begin{abstract}
Resumo. A efervescência desses temas se faz em razão da adoção, nos últimos tempos, de políticas públicas de dignidade humana e de inclusão social às pessoas com deficiência ou mobilidade reduzida. Nessa direção, o presente trabalho tem como proposta analisar, através de imagens que circularam/circulam na mídia, os modos de instalação do sujeito deficiente, em especifico o cadeirante e o surdo, através das políticas que primam pela dignidade e inclusão da pessoa com deficiência, propostas pelo Estado. $O$ referencial teórico é o da Análise de Discurso de linha materialista, iniciada por Michel Pêcheux, na França, e ampliada por Eni Orlandi, no Brasil. Pela análise, pretendemos mostrar, então, que a situação de dignidade e de inclusão do sujeito deficiente passa antes por uma educação geral da sociedade - da família, da escola e de todos os meios sociais - que é tarefa e responsabilidade do Estado, uma vez que o funcionamento dos discursos e das práticas sociais determina, nos materiais analisados, os processos de inclusão/exclusão social dos deficientes, que, por seus modos distintos de relacionar-se com o espaço e com a sociedade, necessitam não apenas de leis, mas de educação social para que haja o exercício pleno da sua dignidade e da sua inclusão.
\end{abstract}

Palavras-chave: Inclusão social. Dignidade humana. Leis de acessibilidade.

\begin{abstract}
The effervescence of these topics is done by reason of the adoption, in recent times, public policies of human dignity and social inclusion for people with disabilities or reduced mobility. That way, the present work has as its proposal to analyze, through images that circulated circulating in the media, the subject institution modes disabled, specifically the wheelchair and the deaf, through policies that are conspicuous by their dignity and inclusion of disabled person, proposed by the State. The theoretical analysis of the Discourse of materialistic line, initiated by Michel Pêcheux, in France, and expanded by Eni Orlandi, in Brazil. For analysis, we intend to show that the situation of dignity and inclusion of the handicapped guy going on before by
\end{abstract}

\footnotetext{
${ }^{1}$ Docente do Programa de Pós-graduação em Linguística - PPGL/Unemat/Cáceres -MT.

${ }^{2}$ Discente do Programa de Pós-graduação em Linguística - PPGL/Unemat/Cáceres -MT.
} 
a general education of society - the family, school and social media-it's task and responsibility of the State, since the operation of discourses and social practices determines, in the materials analyzed, the processes of inclusion and exclusion of disabled people, which, in their different ways to relate with the space and society, require not only of laws, but of social education for the full exercise of their dignity and their inclusion.

Keywords: Social inclusion. Human dignity. Accessibility laws.

\section{LINHA CRONOLÓGICA DA HISTÓRIA DA DEFICIÊNCIA}

A forma como a deficiência é, atualmente, conceitualizada e definida derivou de um longo processo, resultante de diversas reformas políticas e sociais, ao longo da história da humanidade. Ao analisar a linha cronológica da história da deficiência, percebe-se que as pessoas com deficiência passaram por diversos momentos, havendo períodos em que as crianças com deformações físico-mentais eram mortas ou abandonadas a sua sorte, até momentos em que a deficiência era tida como uma provação divina. Desse modo, o entendimento sobre a deficiência foi interpretado como um pecado, um castigo ou erro cometido pelos pais ou família, de modo que as pessoas com deficiência foram isoladas, marginalizadas e desvalorizadas pela sociedade (VEIGA, 2006).

Ainda, de acordo com o autor, registra-se que o movimento de conscientização da necessidade das pessoas com deficiência ou mobilidade reduzida foi iniciado na Europa, por volta de 1902 a 1912, através da instalação e organização de instituições voltadas para o preparo dessas pessoas. Desse modo, fundos foram levantados com o propósito de garantir a manutenção dessas instituições, havendo uma preocupação crescente com as condições dos locais onde as pessoas com deficiência se abrigavam, dando mostras de que essas pessoas precisavam participar ativamente do cotidiano e integrarem-se à sociedade. O movimento se deu, então, de uma segregação radical para o simulacro de uma integração, pois, indubitavelmente, a integração promoveu avanços, mas não tardou a ser substituída por uma forma de assistencialismo mais nefasto e mais discriminatório.

Dessa maneira, a história da deficiência passou da segregação absoluta para a fase da pseudo-integração - o deficiente passou a ser "integrado", para produzir, para a sociedade e para o próprio deficiente, o efeito de que ele estava integrado, de que ele participava, de que ele pertencia - para, posteriormente, fazer instalar a fase de inclusão.

No Brasil, a fase de inclusão aconteceu, sobretudo, com as políticas de inclusão da pessoa com deficiência, que ocorreram em meados do século XX até os dias atuais. Dentre essas leis podemos observar, mais recentemente,

- O Decreto $n^{\circ}$. 5.626, de 22 de dezembro de 2005, que regulamenta a Lei $n^{\circ} 10.436$, de 24 de abril de 2002 e que dispõe sobre a Língua Brasileira de Sinais (LIBRAS), através do art. 18 da Lei $\mathrm{n}^{\circ} 10.098$, de 19 de dezembro de 2000;

- O Decreto $n^{\circ}$. 5.296, de 02 de dezembro de 2004, que regulamenta a Lei $\mathrm{n}^{\mathrm{o}}$ 10.048/2000, dando prioridade de atendimento às pessoas com deficiência;

- E a Lei $n^{\circ} 10.098 / 2000$, que estabelece normas gerais e critérios básicos para a promoção da acessibilidade das pessoas com deficiência ou com mobilidade reduzida. 
O fato perceptível é o de que as políticas governamentais, implantadas para garantir a inclusão desses sujeitos deficientes, acabaram por instituir, através de uma enormidade de Decretos, Regulamentos, Normativas e Leis, sentidos constituídos por funcionamentos histórico-ideológicos do deficiente/ da deficiência que fizeram/fazem funcionar, em maior ou menor grau, uma memória que faz eco na história de rejeição, de abandono e de assistencialismo reservado a esse público.

Nessa direção, parece-nos necessário compreender como o sujeito deficiente foi/é significado pela mídia brasileira, para, enfim, analisarmos os sentidos instalados pelos enunciados e imagens (linguagem verbal e não verbal), que fazem circular sentidos para o deficiente/a deficiência, e que dizem do acesso, da relação de pertença, enfim, dos modos de sua inclusão/exclusão social.

\section{ACESSIBILIDADE E DEFICIÊNCIA: A MÍDIA COMO LUGAR DISCURSIVO}

A inobservância das propostas de políticas públicas governamentais de acessibilidade fez/faz com que o sujeito deficiente, especialmente o cadeirante e o surdo, se constitua como sujeito da ineficiência, da dependência, da exclusão, como será analisado pelas imagens e pelos enunciados que lhe determinam sentidos, no social. Pelo material analisado, o funcionamento que se coloca em visibilidade, faz parte de um discurso sobre o deficiente, produzindo sentidos de que o sujeito deficiente se vê e se significa aos modos do que se discursiviza sobre ele.

De acordo com Orlandi (2009, p. 83), esses modos de silenciar o deficiente fazem parte do que a autora denomina como silêncio constitutivo, "[...], pois uma palavra [ou imagem] apaga outras palavras". Assim, entre o que é dito e o que não é dito ou é silenciado, o deficiente, físico e auditivo, se move e se imobiliza nesses espaços de discriminação e de não aceitação em que ele é dito/interpretado/calado pelo outro.

Dessa maneira, visualizaremos, através das imagens analisadas, os modos como o deficiente, na sociedade atual, é significado pelo outro, a partir de sentidos instalados histórico-ideologicamente, marcando efeitos de aceitação e de resistência em relação à imagem do deficiente para o outro e para si próprio. São, pois, esses sentidos, instalados pela ideologia na história, que pretendemos tornar visíveis, pelos dispositivos teóricos da $\mathrm{AD}$, que nos permitirão compreender os modos como o verbal e o não verbal se complementam para produzir efeitos de sentido de uma certa dignidade e uma certa inclusão para o sujeito deficiente.

Para a discussão da injunção entre o verbal e o não verbal, na constituição dos sentidos sobre a deficiência/o deficiente, tomaremos as formulações e as imagens como acontecimentos discursivos ${ }^{3}$ que, por si só, instalam sentidos para as pessoas com mobilidade reduzida, pois a imagem sobre o deficiente instala sentidos que se atravessam de uma memória que o inscreve/filia a um dado funcionamento discursivo, ditado pelo

\footnotetext{
${ }^{3}$ Orlandi (2009, p. 28) define como acontecimento discursivo o "[...] ponto de encontro entre uma atualidade e uma memória".
} 
Estado, ou seja, aquele que o individualiza, pelas suas diferenças, enquanto um ser que necessita de atendimentos especiais (nas filas, nos assentos, nos estacionamentos etc.).

Nesse entendimento, ativa-se uma memória discursiva, que possui, segundo Orlandi (2009, p. 30), características particulares quando pensada em relação ao discurso, ou seja, é tratada como interdiscurso: "[...] aquilo que fala antes, em outro lugar, independentemente. [...] o saber discursivo que torna possível todo dizer e que retorna sob a forma do pré-construído, o já-dito que está na base do dizível, sustentando cada tomada da palavra".

Nesta direção, a autora afirma que

[...] o interdiscurso determina a formação discursiva, dissimulando na transparência do sentido, a objetividade material contraditória do interdiscurso que a determina. [...]. O interdiscurso é irrepresentável. Ele é constituído de todo dizer já-dito. Ele é o saber, a memória discursiva (ORLANDI, 2006, p. 18).

Para compreendermos o funcionamento do interdiscurso nas imagens que instalam sentidos para o deficiente/a deficiência, trazemos o recorte:

\section{FIGURA I}

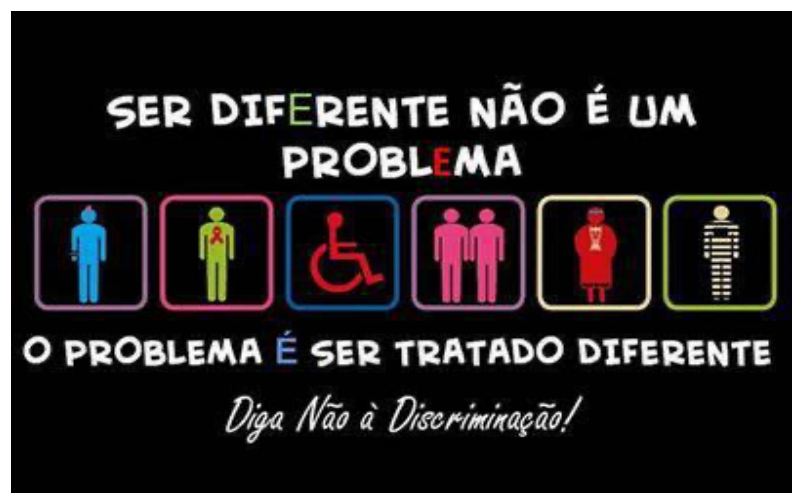

Nosso primeiro gesto de análise centra-se na mensagem verbal da imagem publicitária:

Ser diferente não é um problema.

O problema é ser tratado diferente.

A marcação da letra e na cor vermelha em - Ser Diferente não é um problema produz efeitos de sentido que foram/são instalados histórico-ideologicamente, visto que essa cor, a mais recorrente em imagens publicitárias, segundo o Dicionário de Símbolos ${ }^{5}$, marca-se, em termos gerais, como uma cor estimulante, que simboliza coragem, juventude, criatividade e desejo. Mas, essa cor traz em si mesma uma ambiguidade constitutiva, pois, na tonalidade clara, ao mesmo tempo que representa o amor, a paixão e a sorte, na tonalidade escura, representa a guerra e o perigo. Esses sentidos, que

\footnotetext{
${ }^{4}$ Disponível em: http://sereduc.com/LcydRj. Acesso em 28 mar. 2018.

${ }^{5}$ Significado das cores. Disponível em: https:/www.dicionariodesimbolos.com.br/significado-cores/. Acesso em 26 out. 2020.
} 
remontam à história e à ideologia, conferem ambivalência à cor vermelha, de modo que, no dizer, ela produz efeitos de algo que ata e, ao mesmo tempo, liberta o sujeito deficiente dos problemas, dos limites que a deficiência lhe impõe. Assim, o emprego da cor vermelha, no e da palavra problema, pode marcar as guerras diárias, os conflitos, as situações de batalhas que o deficiente tem de enfrentar cotidianamente.

Desse modo, para a pessoa com deficiência ou mobilidade reduzida viver em sociedade, construir seu espaço e marcar a sua história é necessário que ele supere as condições adversas a que é constantemente exposto e que enfrente os descasos e as omissões dos governantes. A cor vermelha, marcada historicamente pelas posições revolucionárias e transformadoras, em contraste com a cor branca (que significa rendição e paz, exprimindo calma, frescura e pureza) remete o sujeito deficiente a uma situação de constante apelo à vida, ao futuro, a uma posição de luta.

Se no semáforo a cor vermelha significa pare!, o parar não tem o sentido de estagnação, de acomodação, mas de apelo e de manutenção da vida, pois parar ali tem o sentido de continuar vivendo, de manutenção da vida. Parar, nesse caso, significa estar em acordo com a regulamentação do trânsito, parar para pertencer, para ser cidadão, para funcionar conforme o que dita a voz de Estado.

Do mesmo modo, a cor vermelha na palavra problema se volta sobre o significado da própria palavra, pois o pare faz escopo sobre a palavra problema, fazendo funcionar sentidos que remetem à necessidade de parar de tomar a deficiência como um problema - pare de tomar a deficiência como problema, ou, a deficiência não é um problema.

A cor vermelha no cartaz produz, então, esse duplo que é próprio à pessoa com deficiência ou com mobilidade reduzida, pois, se ser diferente não é um problema, ser tratado como diferente é problema. O e em "problema" também produz sentidos em relação a uma memória que conforma a exclusão social a qual o deficiente foi sempre exposto. A letra "e" produz, nessas condições de produção, sentidos através de uma memória discursiva sobre os problemas sociais, pois, na imagem analisada, não é só o deficiente físico que sofre a discriminação social, mas também o idoso, o presidiário, o homossexual, o aidético etc.

A linguagem verbal (formulação) expressa um funcionamento que produz efeitos de desresponsabilização, tanto do Estado quanto da sociedade em geral, para com o sujeito deficiente, pois atribui ao outro, que o discrimina, todo o problema da deficiência. O problema não é, pois, a deficiência e as condições de acesso, mas ser tratado de forma diferente. Dessa maneira, a autonomia e a independência de mobilidade do deficiente são atribuídas ao processo de discriminação produzido pelo outro, assim, se responsabiliza a discriminação e, indiretamente, o próprio sujeito deficiente, apagando as diferenças e desobrigando o Estado a proporcionar-lhe a condição de acesso, pois todo o problema se coloca como responsabilidade do outro, que discrimina, que rechaça.

No cartaz, o funcionamento das imagens (não verbal) e das formulações (verbal) produzem efeitos de um discurso sobre, um discurso que cala o deficiente, que o silencia em seus desejos e necessidades, apagando seus modos distintos de relacionar-se com os espaços e com a sociedade, atribuindo ao outro toda a responsabilidade de um possível fracasso do sujeito com deficiência. 
Nesta direção, constrói-se um espaço discursivo para a repetição dos saberes sobre a questão da deficiência e dos seus efeitos de sentidos, pois essa rede discursiva de formulações não permite perceber o trabalho da resistência dos deficientes, tanto os cadeirantes, os com mobilidade reduzida quanto os surdos. Ao se formular que todo o problema da deficiência reduz-se aos modos de tratamento diferenciado dispensado ao deficiente, apaga-se, inclusive, qualquer possibilidade de luta, de revolta, de resistência, por parte do próprio deficiente que fica silenciado por suas condições de produção: a de carregar o ônus de uma discriminação e de uma rejeição que o imobiliza, pois silenciar o deficiente é retirar-lhe qualquer possibilidade de voz, visto que, conforme afirma Pêcheux (1988, p. 32), “[...] a revolta é contemporânea à linguagem" e a impossibilidade de pertencer, de ser do grupo, impossibilita qualquer reação ao sujeito deficiente.

A mídia é, enquanto lugar discursivo, atravessada por discursividades díspares que representam diferentes lugares sociais, diferentes posições-sujeito e diferentes formações ideológicas. Com isso, o discurso por ela produzido nunca será o do cadeirante nem o do surdo, mesmo que o discurso apresente-se, formalmente, como tal e que permita reconhecer nele saberes da pessoa com deficiência.

Dessa maneira, a mídia tem um funcionamento recorrente de modo a produzir uma ilusão de "unidade", visto que a mídia digital, tal como qualquer outra mídia, funciona de modo a aparentar isenção na mediação entre o seu leitor e a realidade, quando, de fato, não há isenção, visto que cada veículo de propagação de notícias veicula, junto à notícia, sua ideologia. Assim, os textos midiáticos produzem uma ilusão de realidade e de isenção para narrar os fatos, enquanto fornece ao leitor, pela ordem do simbólico, o simulacro de representação da sua relação com a realidade concreta.

As mídias funcionam, cada qual com sua especificidade, de modo a instituir o acontecimento discursivo, pois instalam-se, permanentemente, pela relação necessária da língua com a história, colocando em relação uma atualidade e uma memória, de modo a presentificar o que deve ser lembrado e o que deve permanecer esquecido. Assim, o seu papel não é de isenção, mas de memorização do que deve ser mantido na lembrança e do que deve ser apagado, silenciado, conforme a ideologia que a conforma.

Pela instantaneidade da notícia, a mídia interpela incessantemente o sujeito leitor, compondo, através de textos verbais e não-verbais, o movimento da língua com a história, da atualidade com a memória, instalando efeitos identitários, que nascem e se instituem pela movimentação dos sentidos e dos sujeitos.

Nessa direção, a representação do sujeito deficiente pela mídia, do processo de segregação, ao de integração e ao de inclusão, será sempre constituída por esse lugar discursivo que o toma por um discurso sobre o deficiente/a deficiência, um sujeito que é imbricado e construído pela relação da língua com a história. Trata-se, pois, de um sujeito que não se inscreve em uma formação discursiva determinada, mas que é atravessado por sentidos e por saberes que se constituem como ecos de diferentes formações discursivas, o que caracteriza o seu discurso como sendo ideologicamente heterogêneo e marcado por contradições. 
Assim sendo, o discurso do sujeito deficiente, ao ser reportado para este lugar, é fragmentado e diversificado e está sujeito a constantes marcações de ordem ideológica. Nesse funcionamento, a mídia, sempre alerta, coloca-se, então, na posição de juíza e sentencia, opera, com conduta de veracidade, a questão da deficiência/do deficiente como concernida aos movimentos sociais.

Nesse entendimento, as cores utilizadas no cartaz marcam ainda a posição do deficiente/diferente na sociedade: o e em vermelho, na palavra problema, marca-se como lugar de desresponsabilização do Estado para a responsabilização do outro, que discrimina, portanto, um lugar de luta social. Enquanto o e em azul - em "O problema é ser tratado diferente" - marca, segundo o Dicionário de Símbolos ${ }^{6}$, a abertura para as relações sociais, significando o processo de abertura do deficiente para a inclusão social, ou seja, todo o problema se reduz às relações sociais de aceitação/não aceitação do deficiente, eximindo qualquer responsabilidade pelo Estado.

A linguagem não verbal (cores e formato), presentes na imagem, permite-nos compreender que o que se coloca em funcionamento, pela produção de efeitos de sentido, são silenciamentos dos desejos e das vontades do sujeito deficiente/diferente, uma vez que ele é dito, é falado pelo outro. Segundo Indursky (2011, p. 178), esses funcionamentos se

[...] significam como memória discursiva, ou seja, a interpretação, o sentido já está lá, a discursividade prévia é mobilizada para interpretar essas imagens, como todo e qualquer discurso, pressupõe sentidos anteriores que são mobilizados, na qualidade de pré-construído, para interpretação de discursividade imagéticas.

Nesse contexto, os sentidos ambivalentes das cores utilizadas nas imagens dizem do funcionamento histórico-ideológico da deficiência, ou seja, do lugar da aceitação e do rechaço. Desse modo, a frase - "Ser diferente não é problema, o problema é ser tratado diferente" - a palavra problema faz remissão ao percurso histórico da deficiência no Brasil: o da interação ao da inclusão, o qual torna visível, pela análise, o funcionamento dos modos de tratamento dispensado ao sujeito deficiente, um tratamento instituído pelo sentimento de pena, de abandono, de discriminação, ou seja, da integração à inclusão o que se observa são gestos que mais excluem do que incluem, pois, de todo o modo, o deficiente continua sem voz, continua sendo falado pelo outro, continua não pertencendo, apesar de a legislação assegurá-lo como sujeito-de-direito. Assim, são sentenciados, segundo Foucault (1998, p. 80), a serem "[...] julgados, condenados, classificados, obrigados a desempenhar tarefas e destinados a um certo modo de viver ou morrer em função de discursos verdadeiros que trazem consigo efeitos específicos de poder”.

Podemos afirmar, então, que as palavras são povoadas de sentidos, tanto pelo que é dito quanto pelo que é silenciado. O silêncio, que atravessa as palavras, que passa por elas ou que indica que o sentido pode ser outro, marca o que pode e o que deve ser dito. Trata-se do silêncio fundador, que conforma o não dito, o que é visto no interior da

\footnotetext{
${ }^{6}$ Para o Dicionário de Símbolos, “[...] o azul representa tanto a expansão do céu como as profundezas do mar. Simboliza espiritualidade, pensamento, infinito, vazio, eternidade e transparência”. Disponível em: https://www.dicionariodesimbolos.com.br/significado-cor-azul/. Acesso em 26 out. 2020.
} 
linguagem, um silêncio significante, que tem significância própria, pois, “[...] o silêncio $e ́$. Ele significa [...], [pois], no silêncio, o sentido é" (ORLANDI, 1993, p. 33). Ainda nessa direção, encontramos o silêncio passando não pelas palavras, mas pelo gesto ${ }^{7}$ significativo da coerção.

Para pensarmos o avanço/retrocesso da integração para a inclusão e os modos de funcionamento do silêncio, trazemos outra imagem que questiona a inclusão na escola:

FIGURA $2^{8}$

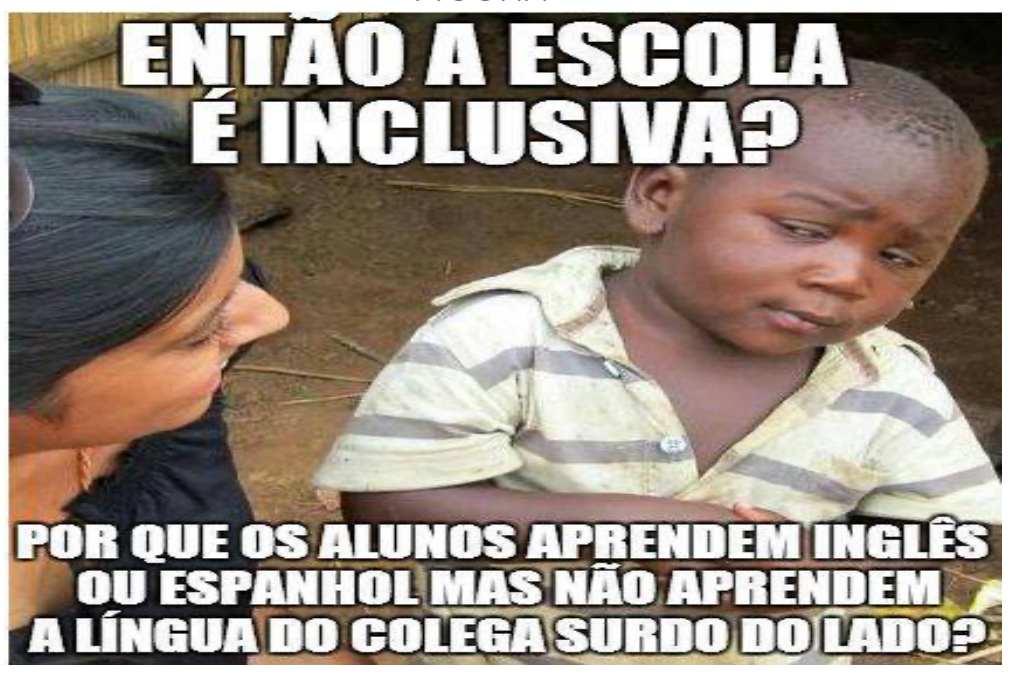

Nesta imagem, a voz do Estado é questionada pelos modos de inclusão que se dá na escola: "então a escola é inclusiva?", pois sendo a escola um Aparelho Ideológico do Estado, conforme preconiza Althusser (1985), a pergunta, que é da ordem do verbal, juntamente com a imagem, da ordem do não verbal, funciona, nesse cartaz, como modo de dizer da inoperância do Estado frente ao processo de inclusão. Pelo não verbal temos, de um lado, o aluno, de expressão arredia, desconfiada, frente, ao que se supõe, a professora. Pelo verbal, coloca-se, pelo funcionamento do se $\sim$ então, em duas perguntas que funcionam como afirmação, a paráfrase - se a escola é inclusiva então porque os alunos não podem falar com o colega surdo. Dito de outra maneira, a inclusão que se dá nas escolas não é satisfatória ou não é total, pois os alunos surdos, por exemplo, que se comunicam por uma língua específica, a língua de sinais (LIBRAS), estão impedidos de falar com os colegas ouvintes, pois a escola não se preocupou em ensinar àqueles a língua dos surdos. Assim, o cartaz faz referência ao aprendizado de línguas estrangeiras na escola - o inglês, o espanhol -, que deveria habilitar os alunos para falarem com moradores de outros países, mas que não o preparam para falar - pela Libras - com o colega surdo que está do seu lado.

Desse modo, pelo não verbal, a expressão de desconfiança do aluno para com a professora pode ser tomada como expressão de incompreensão, pois a professora, tal como os colegas, na maioria das vezes, também desconhece a língua de sinais e tenta falar com o aluno surdo como se ele fosse um ouvinte. Ou seja, a inclusão, nesses moldes, funciona como integração, pois as condições mínimas de ensino-aprendizagem não foram

\footnotetext{
${ }^{7}$ O gesto é, conforme Pêcheux (1975), aquilo que “[...] intervém no real do sentido".

${ }^{8}$ Disponível em: https:/www.facebook.com/librasavante/photos/-como-pode-haver-inclus\%C3\%A3o-seos-alunos-da-escola-n\%C3\%A3o-aprendem-libras/1011677832234755/. Acesso em 28 mar. 2018.
} 
dadas e professores e alunos não conseguem comunicar e ensinar/aprender com a pessoa com deficiência e o que se faz pelo deficiente é colocá-lo em situação de assistência em que tudo é feito, falado e entendido por ele.

Dessa maneira, as políticas de ensino, que deveriam ser exercidas conforme as regularidades das instituições do país, não se concretizam, de fato, em sala de aula em razão de diversas causas: a ambiência escolar limitada, os profissionais sem capacitação adequada para atender a demanda dos alunos com deficiência, enfim, a própria legislação, que vai na contramão desta realidade vivenciada, muitas vezes, na escola.

O fato de um aluno negro compor o cartaz também não é trivial, pois o efeito produzido é o de que a inclusão se faz sobre qualquer minoria apartada das relações sociais, assim, a imagem do aluno negro representa a inclusão social e educacional de uma parte da população que, em maior ou menor grau, esteve alijada do processo de escolarização. Nesse entendimento, o cartaz traz para o sentido de inclusão uma compreensão muito mais ampla do que o da inclusão da pessoa com deficiência, pois além de usar a imagem de um aluno negro, uma classe também excluída, fala ainda sobre a necessidade de se incluir pela língua estrangeira (o inglês ou o espanhol), que são línguas que permitem o acesso ao mundo dos negócios, das tecnologias etc.

O discurso verbal, presente na frase - "Por que os alunos aprendem inglês ou espanhol, mas não aprendem a língua do colega surdo do lado"? - marca uma inversão nos valores culturais, assinalada pela presença da conjunção adversativa "mas", pois, se por um lado a escola ensina a língua dos negócios, da ciência, do Mercosul, por outro, ela faz uma inclusão que nega aos seus beneficiários - os alunos de todos os credos, todas as etnias, todas as culturas, todas as deficiências - o direito de se comunicarem livremente, de se entenderem mutuamente, pois a busca frenética por uma outra língua - a inglesa ou a espanhola - o pretenso domínio ${ }^{9}$ da língua do capitalismo, negou/nega aos alunos falarem, aprenderem, entenderem, por exemplo, a língua do colega surdo que está ao seu lado.

Nessa direção, a sociedade como um todo aparta do convívio social os deficientes, em especifico o cadeirante e deficiente auditivo, colocando-os, muitas vezes, em uma posição de intruso, assim, exclui, com muita naturalidade, o ser humano do convívio social, exatamente por vê-lo como diferente, como incompleto.

Trata-se, pois, de uma questão de construção de uma identidade para alunos e professores, na escola. Contudo, como adverte Silva (2000, p.73),

[...] a busca pela identidade implica um movimento de construção simbólica e discursiva e são, frutos de uma relação social, que possui um vínculo estreito com o poder. Assim a definição da identidade e a marcação da diferença não podem ser separadas das relações mais amplas de poder, ou seja, tanto a construção discursiva da identidade quanto da diferença não é inocente, uma vez que elas requerem uma série de procedimentos que trazem essas noções, tais como:

\footnotetext{
${ }^{9}$ É fato que o ensino de língua inglesa ou espanhola nas escolas da rede não garante o aprendizado dessas línguas, mas esta é uma outra questão, pois o que se discute aqui é o fato de a escola dita inclusiva dispensar toda uma carga horária para o aprendizado dessas línguas e não facilitar aos alunos e professores o acesso, por exemplo, à língua de sinais.
} 
inclusão/exclusão, demarcação de fronteiras, classificação, puros e impuros, logo implica em dizer que "o que somos" significa também dizer "o que não somos".

Ensinar, então, a escola a ser inclusiva, preparar professores e alunos ouvintes para receberem os não ouvintes é antes uma questão de poder, pois depende do que as políticas públicas consideram, de fato, como inclusão.

Segundo Cromack (2004, p. 2), a dificuldade de se lidar com o sujeito surdo nas escolas regulares se faz em razão de se transitar entre as duas culturas - a surda e a ouvinte - sem parar para se pensar nas necessidades específicas de cada uma delas. Para o autor, a identidade do surdo "[...] se constitui com a consciência de ser definitivamente diferente por necessitar de recursos completamente visuais. Essa oscilação entre os surdos e os ouvintes faz com que o sujeito surdo constitua, por vezes, sua identidade de forma fragmentada".

Essa fragmentação da identidade é o processo que se tem observado na escola, em razão de uma medida inclusiva, por parte das políticas de Estado, que se deu aos moldes da interação. Contudo, parece necessário que a escola se adeque às necessidades de cada sujeito, pois, somente os movimentos integradores da identidade da pessoa com deficiência dará conta de reverter e de dar consequência produtiva às políticas de inclusão.

Skliar (1998, p. 66) denomina esse processo de fragmentação como identidade flutuante e o aponta como o fator que dificulta a adaptação do aluno surdo na escola regular:

[...] o surdo não está a serviço da comunidade ouvinte por falta de comunicação e nem a serviço da comunidade surda por falta da língua dos sinais. [...] [O surdo acaba] construindo sua identidade com fragmentos das múltiplas identidades de nosso tempo, não centradas, mas sem um elemento integrador como a linguagem e sua capacidade de significação.

Não falar a língua de sinais impõe um funcionamento que é da ordem da própria língua e não apenas a repetição secular de preconceitos e de segregações, mas, é aí mesmo que acontecem as disjunções, as divisões, os conflitos e as regularidades que nem sempre se adequam ao sujeito surdo, acabando muitas vezes por deslocá-lo e por impedi-lo do convívio social.

\section{CONSIDERAÇÕES FINAIS}

O recorte, através do nosso gesto de leitura, permitiu-nos compreender os efeitos de sentido postos em circulação por essas imagens e por essas formulações, que, pelo processo sócio-histórico-ideológico que as instituiu, instalaram/instalam sentidos para os sujeitos deficientes e para a deficiência.

A posição teórica que assumimos permitiu-nos produzir um gesto de interpretação que toma a instalação da imagem e das formulações para a deficiência como acontecimento discursivo, ou seja, como um discurso, que produz efeitos entre locutores. 
Nessa direção, a Análise de Discurso possibilitou-nos dar visibilidade aos discursos colocados em funcionamento pelas imagens e pelas formulações, marcadas por diferentes posições-sujeito, permitindo compreender os efeitos de sentido que as campanhas públicas, oficialmente determinadas para a deficiência física e visual, produzem por/para os sujeitos.

O funcionamento do discurso, proposto pela Análise de Discurso, determina, nas materialidades analisadas nessa pesquisa, os processos de inclusão/exclusão social dos deficientes, que apresentam modos distintos de relacionar-se com o espaço e com a sociedade.

Orlandi (2001), ao teorizar sobre as formas de o sujeito deficiente significar o seu corpo e ocupar os espaços, ressalta a ocorrência de um estranhamento social, quando um determinado território é invadido por indivíduos que são a ele estranhos, como é o caso das pessoas com deficiência. Assim, esse acontecimento inesperado de ocupação do espaço, por um corpo não autorizado por uma relação de pertença, produz sentidos que vão funcionar como protesto deste sujeito deficiente para com a sociedade.

Para Orlandi (2007, p. 9), a linguagem tem uma relação necessária com os sentidos e, pois, com a interpretação, uma vez que é sempre passível de equívoco. Dito de outro modo, os sentidos não se fecham, não são evidentes, embora pareçam ser. Além disso, eles jogam com a ausência, com os sentidos do não sentido.

\section{REFERÊNCIAS}

ABNT-NBR 9050. Norma Brasileira. Acessibilidade a edificações, mobiliário, espaços e equipamentos urbanos. $2^{\mathrm{a}}$ ed. Brasília, 2004.Disponível em http://acessibilidade.sigaessaideia.org.br/. Acessado em 20/03/2012.

ALTHUSSER, Louis. Aparelhos ideológicos de Estado. São Paulo, SP: Editora Graal, 1985.

BERTICELLI, Ireno Antônio. A origem normativa da prática educacional na linguagem. Ijuí: Editora Unijuí, 2004.

BLANCO, Rosa. Aprendendo na diversidade: implicações educativas. [2002]. Disponível em: $<\mathrm{http} / /$ :www.entreamigos.com.br/educação.htm>. Acesso em: 04/05/2002.

BRASIL. Ministério do Trabalho e Emprego (MTE) \& Secretaria de Inspeção do Trabalho (SIT). A inclusão de pessoas com deficiência no mercado de trabalho. $2^{\mathrm{a}}$ ed. Brasília, 2007. Disponível em http://www.presidencia.gov.br/legislacao. Acessado em 20/03/2012.

BRASIL. Ministério do Turismo. Secretaria Nacional de Políticas de Turismo. Turismo e acessibilidade: Manual de Orientações, $2^{\mathrm{a}}$ ed. Brasília, 2006. Disponível em http://www.acessobrasil.org.br/. Acessado em 20/03/2012.

BRASIL. Saberes e Práticas da Inclusão: Dificuldades Acentuadas de Aprendizagem: Deficiência Múltipla. 2. ed. rev. - Brasília: MEC, SEESP, 2003.

BRASIL. Ministério da Educação. Secretaria de Educação Especial. Sala de Recursos Multifuncionais: espaços para o Atendimento Educacional Especializado. Brasília: MEC/SEESP, 2006. 
BUENO, José Geraldo S. Educação especial brasileira: integração/segregação do aluno diferente. Disponível em http://www.fundaciononce.es. Acessado em 17/10/2011.

CHEVALIER, Jean. Dicionário de Símbolos. Ed. 24. Rio de Janeiro: Editora: EJO JOSE OLYMPIO, 2009.

CROMACK, Eliane Maria Polidoro da Costa: Identidade, Cultura Surda e Produção de Subjetividades e Educação: Atravessamentos e Implicações Sociais. (2004): $<$ http://www.entreamigos.com.br/educação.htm>. Acesso em: 04/02/2014.

DICIONÁRIO DE SÍMBOLOS. Disponível em: https://www.dicionariodesimbolos.com.br/significado-cor-azul/. Acesso: 26 out. 2020.

FOUCAULT, Michel. A arqueologia do saber. Trad. Luiz Felipe Baeta Neves. Petrópolis: Vozes; Lisboa: Centro do Livro Brasileiro, 1972.

FOUCAULT, Michel. Vigiar e Punir: história da violência nas prisões. 24 ed. Petrópolis: Vozes, 2001.

INDURSKY, Freda: “A representação do MST na mídia: discurso verbal e não verbal". Leituras do político/organização(e) Lucília Maria Sousa Romão. - Porto Alegre: Editora da UFRGS, 2011.

MENDES, Enicéia G. A educação inclusiva e a universidade brasileira. Disponível em http://www.fundaciononce.es. Acessado em 17/10/2011.

ORLANDI, Eni P. Análise de discurso: princípios e procedimentos. Campinas, SP: Pontes Editores, 2009.

ORLANDI, Eni P. Interpretação: autoria, leitura e efeitos do trabalho simbólico. Campinas, SP: Pontes Editores, 2007.

ORLANDI, Eni P. Cidade dos sentidos. Campinas, SP: Pontes Editores, 2004.

PÊCHEUX, Michel. "Discurso e ideologia". In: Semântica e discurso: uma crítica à afirmação do óbvio. (trad.) Eni Orlandi. 2a ed. Campinas: Editora da UNICAMP, 1995.

PÊCHEUX, Michel. "Papel da Memória". In. Papel da Memória. Campinas, SP: Pontes Editores, 1999.

PÊCHEUX, Michel. O discurso: estrutura e acontecimento. Campinas: Pontes, 1990.

SILVA, Thomas T. da. A produção social da identidade e da diferença.in:

(org.). Identidade e diferença: a perspectiva dos estudos culturais, Petrópolis: Vozes, 2000, p.73-102.

SKLIAR, Carlos. Os Estudos Surdos em Educação: Problematizando a Normalidade. In: (org.). A Surdez: um Olhar Sobre as Diferenças. Porto Alegre: Mediação, 1998, p. 7-32.

Artigo recebido em: jun. de 2020.

Aprovado e revisado em: out. de 2020.

Publicado em: dez. de 2020.

Para citar este texto:

SILVA, Patrícia Aparecida da; MALUF-SOUZA, Olímpia. Inclusão Social na/pela Mídia: modos de instalação do sujeito deficiente. Entremeios [Revista de Estudos do Discurso, ISSN 21793514, on-line, www.entremeios.inf.br], Seção Estudos, Programa de Pós-Graduação em Ciências da Linguagem (PPGCL), Universidade do Vale do Sapucaí (UNIVÁS), Pouso Alegre (MG), vol. 22, p. 122-133, jul. - dez. 2020.

DOI: http://dx.doi.org/10.20337/ISSN2179-3514revistaENTREMEIOSvol22pagina122a133 